\title{
Effects of Prolonged Sleep Deprivation on Local Rates of Cerebral Energy Metabolism in Freely Moving Rats
}

\author{
Carol A. Everson, ${ }^{1}$ Carolyn Beebe Smith, ${ }^{2}$ and Louis Sokoloff ${ }^{2}$ \\ ${ }^{1}$ Clinical Psychobiology Branch and 'Laboratory of Cerebral Metabolism, The National Institute of Mental Health, National \\ Institutes of Health, Bethesda, Maryland 20892
}

\begin{abstract}
Although sleep deprivation interferes with biological processes essential for performance, health, and longevity, previous studies have failed to reveal any structural or functional changes in brain. We have therefore measured local rates of cerebral glucose utilization $\left(\right.$ (CMR $_{\mathrm{glc}}$ ) with the quantitative autoradiographic $2-{ }^{14} \mathrm{C}$-deoxyglucose method in an effort to determine if and, if so, where sleep deprivation might affect function in sleep-deprived rats. Sleep deprivation was maintained for 11-12 d, long enough to increase whole body energy metabolism, thus confirming that pathophysiological processes that might involve brain functions were evolving. Deep brain temperature was also measured in similarly treated rats and found to be mildly elevated relative to core body temperature. Despite the increased deep brain temperature, systemic hypermetabolism, and sympathetic activation, ICMR glc $_{\text {was not elevated in any of the } 60}$ brain structures examined. Average glucose utilization in the brain as a whole was unchanged in the sleep-deprived rats, but regional decreases were found. The most marked decreases in $1 \mathrm{CMR}_{\text {olc }}$ were in regions of the hypothalamus, thalamus, and limbic system. Mesencephalic and pontine regions were relatively unaffected except for the central gray area. The medulla was entirely normal. The effects of sleep deprivation on brain tended, therefore, to be unidirectional toward decreased energy metabolism, primarily in regions associated with mechanisms of thermoregulation, endocrine regulation, and sleep. Correspondence was found between the hypometabolic brain regions and some aspects of peripheral symptoms.
\end{abstract}

[Key words: sleep deprivation, brain, glucose utilization, whole-body metabolism, autoradiography, deoxyglucose, brain temperature]

Prolonged sleep deprivation impairs cognitive performance (Horne, 1988), and severe sleep disturbances are considered health risk factors that compound disease processes (Miller and Bartus, 1992) and reduce longevity (Kripke et al., 1979). Sleep deprivation is assumed to affect the brain, not only because of cognitive disturbances, but because neural centers for control

Received Jan. 25, 1994; revised Apr. 27, 1994; accepted May 10, 1994.

We express our appreciation to Shari A. Jerrels, Jane W. Jehle, Christina M. Herrero-Backe, Michael A. Jackson, Courtney P. Mudd, and Timothy R. Vamey for their technical assistance.

Correspondence should be addressed to Carol A. Everson, Ph.D., National Institute of Mental Health, Building 10, Room 4S-239, 9000 Rockville Pike, Bethesda, MD 20892.

Copyright $\circledast 1994$ Society for Neuroscience $0270-6474 / 94 / 146769-10 \$ 05.00 / 0$ of sleep and arousal reside in the brain (Steriade, 1992). The mechanisms underlying the adverse effects of sleep deprivation on health and the neurophysiological effects in brain that might account for poor cognitive performance remain, however, obscure.

Sleep deprivation in rats results in a unique constellation of peripheral symptoms that develops progressively and eventually culminates in death after about $19 \mathrm{~d}$ (Rechtschaffen et al., 1983; Everson et al., 1989a). The earliest and most robust and consistent effect is a dramatic increase in whole-body energy expenditure, manifested by voracious eating and loss of body weight (Everson et al., 1989a). This hypcrcatabolism develops progressively and becomes associated with other signs and symptoms, for example, skin lesions (Kushida et al., 1989), hypoalbuminemia (Everson et al., 1988), and bodily wasting(Everson et al., 1989a). Eventually, as debilitation becomes pronounced, body temperature declines even though energy expenditure remains high (Bergmann et al., 1989b), indicating impaired heat retention. Death is precipitated by a breakdown of host defenses that allows indigenous, pathogenic microorganisms into the bloodstream, which presumably sets up a lethal cascade of toxic and deleterious effects (Everson, 1993). There are neither febrile nor substantial tissue inflammatory responses, suggesting that sleep-deprived rats may be immunosuppressed.

Despite these pronounced systemic effects, gross perturbations in the sleep-deprived brain have not been found. Histopathological examinations have not revealed any patterns of structural damage (e.g., cell death or neuronal degeneration) to distinguish sleep-deprived from yoked-control rats, even when death was imminent (Gilliland et al., 1984). No abnormalities in the concentrations and turnover of monamines in brain have been found (Bergmann et al., 1991), and receptor number and affinity of $\alpha_{1^{-}}, \alpha_{2}-$, and $\beta$-adrenergic receptors appear to be unchanged (Tsai et al., 1993). Early gene expression of Egr-1-like immunoreactivity in brains of sleep-deprived rats is not notably different from that of yoked-control rats (Landis et al., 1993). The paucity of biochemical and structural changes suggests that changes in brain due to sleep deprivation, if any, are probably not large or widely distributed, and all the effects of sleep deprivation prior to death are quickly reversed by subsequent sleep (Everson et al., 1989b), suggesting that they are neither permanent nor long lasting.

The human brain requires a large fraction of the total body's basal oxygen consumption to function normally (Sokoloff, 1989). The cognitive deficiencies associated with sleep deprivation in man are easily reversed by subsequent sleep, suggesting a functional and/or metabolic impairment rather than a structural one. 
The pronounced negative energy balance seen in sleep-deprived rats also suggests a metabolic disturbance in chronic wakefulness. We have therefore examined functional and/or metabolic processes in individual structures of the brain in sleep-deprived rats by measuring local rates of cerebral glucose utilization and comparing them to those in yoked controls. The results indicate that the effects of sleep deprivation in brain are heterogeneously distributed among the cerebral structures and that the predominant effects are unidirectional toward decreased energy metabolism, despite a mildly increased brain temperature and a marked rise in catabolic processes in the body as a whole.

Portions of this work were presented previously at the Founding Congress of the World Federation of Sleep Research Societies in Cannes, France, 1991 (Everson et al., 1991).

\section{Materials and Methods}

Animals and surgical procedures. All procedures were carried out in accordance with the National Institutes of Health guidelines on the care and use of animals and an animal study protocol approved by the NIMH Animal Care and Use Committee. Normal male Sprague-Dawley rats weighing $431 \pm 24( \pm \mathrm{SD}) \mathrm{gm}$ and $22 \pm 3( \pm \mathrm{SD})$ weeks old were obtained from Harlan (Frederick, MD). All surgical procedures, including catheter insertions, were performed during a single episode of anesthesia to avoid confounding effects of anesthesia and surgery during the sleep deprivation period. Rats were anesthetized with ketamine. $\mathrm{HCl}(100 \mathrm{mg} / \mathrm{kg}$, i.p.), xylazine $\cdot \mathrm{HCl}(2.4 \mathrm{mg} / \mathrm{kg}$, i.m. $)$, and atropine sulfate $(0.1 \mathrm{mg} / \mathrm{kg}$, i.m.); supplementary doses of ketamine $\cdot \mathrm{HCl}(10 \mathrm{mg} /$ $\mathrm{kg}$, i.p.) were provided as needed. Electrodes to record the cortical EEG, hippocampal theta waves, and temporalis muscle electromyogram (EMG) were implanted to distinguish wakefulness and individual sleep stages. A solution of $1-2 \%$ lidocaine $\cdot \mathrm{HCl}(2.4 \mathrm{mg} / \mathrm{kg})$ was administered subcutaneously in the abdominal incision site through which a low-frequency telemetric transmitter (Barrows, San Jose, CA) was implanted for continuous recording of body temperature. Catheters made from nonthrombogenic polyurethane tubing (Braintree Scientific, Braintree, MA) were inserted into a carotid artery and jugular vein. The arterial catheter was inserted into the left common carotid artery and advanced to the aortic arch. The venous catheter was inserted into the external jugular and advanced to the right atrium. Both catheters were sutured to neck muscles and threaded subcutaneously to exit the scalp at the back of the head, where they were anchored on an electrode head plug assembly, and then extended up along a $45 \mathrm{~cm}$ recording cable. The exposed part of the arterial catheter was protected by a flexible, lightweight spring. Catheters were flushed with heparinized saline containing a small amount of ampicillin $(1.25 \% \mathrm{w} / \mathrm{v})$, four or more times per day for arterial and once daily for venous catheters.

The rats were kept in the apparatus described below under conditions of constant light to diminish the influence of circadian rhythm on the timing of sleep and arousal. Ambient temperature was maintained at $29^{\circ} \mathrm{C}$ by thermostatically controlled heat lamps.

Procedure for producing sleep deprivation and yoked controls. Six sets of experiments, each one on a pair of sleep-deprived and yoked-control rats, were carried out. The duration of each experiment was a 4 week period that included at least $7 \mathrm{~d}$ for recovery from surgery, $7 \mathrm{~d}$ of baseline conditions, and 11-12 d of experimental sleep conditions. The sleep deprivation procedure has been described in detail previously (Rechtschaffen et al., 1983; Bergmann et al., 1989a; Everson and Wehr, 1993). In brief, the paired rats were housed on a large, round, moveable, horizontal platform divided into two halves by a fixed wall. Beneath the platform at a distance of $2 \mathrm{~cm}$ was a pan of water $2-3 \mathrm{~cm}$ in depth, which served as a soft boundary to the perimeter of the platform. The entire apparatus was contained within a large open-air enclosure. The 45-cm-long recording cable connected to the head plug assembly of each rat was attached to a swivel commutator and counterbalanced boom assembly that provided unrestricted movement. Although the rats could move freely and could step down into the shallow water at any time, they normally preferred the platform where they could eat, drink, groom, and sleep easily. During the baseline period, the platform was rotated slowly and automatically once per hour. During the experimental period, the platform was rotated slowly for $6 \mathrm{sec}$ (i.e., one-third revolution) each time sleep onset was detected in the experimental rat by micro- computer assessment of changes in amplitude of cortical EEG, theta, and EMG signals. Because the rats preferred to avoid stepping into the water during rotations, both of them almost always moved to another part of the platform as it passed beneath the dividing cage wall. The platform then remained stationary until sleep onset was again detected in the sleep-deprived rat. Whenever the experimental rat was awake and typically engaged in behaviors, such as eating and grooming, the disk rotation contingencies were not in effect and the yoked-control rat could sleep. If the yoked-control rat was asleep when the experimental rat fell asleep, it, too, was aroused when the disk rotated. In this way the yoked-control rat served as a comparison for the experimental environment and the timing, duration, and frequency of the arousal stimuli.

Wakefulness and sleep stages were scored from digitized EEG, theta, and EMG signals in $30 \mathrm{sec}$ epochs by the Parametric Animal State Scoring System (Bcrgmann et al., 1987). This computer-assisted scoring was validated by visual comparison with $24 \mathrm{hr}$ analog recordings. Continuous measurement of body temperature in $30 \mathrm{sec}$ epochs was obtained from the telemetric transmitters, the signals of which were picked up by AM band receivers, passed through level detectors to discriminate signal from noise, digitized, and timed by a microprocessor (Everson and Wehr, 1993). Core body temperature measurements were aligned with the corresponding sleep stage for each epoch. Only core body temperatures during periods of wakefulness were used for comparison between sleep-deprived and yoked-control rats.

In an attempt to meet the increased total body energy demands and thus prevent the marked loss of body weight and possible secondary responses of the brain to relative starvation during sleep deprivation, rats were fed ad libitum a balanced diet enriched with fat and calories to raise the metabolizable energy content $45 \%$ above that of a normal diet. This dietary modification has previously been shown to attenuate the weight loss and malnutrition-like effects in sleep-deprived rats (Everson and Wehr, 1993). Body weight and food and water intake were recorded daily throughout the baseline and experimental periods. Venous blood (maximum of $1.8 \mathrm{ml}$ ) was sampled daily in experiment 1 or on alternate days $(0.5-0.7 \mathrm{ml})$ in experiments $2-6$ for various chemical analyses in the plasma; the red blood cells recovered from the centrifuged samples were resuspended in heparinized saline and reinjected into the rats to prevent anemia due to blood loss.

Procedure for measurement of local cerebral glucose utilization. After 11-12 $\mathrm{d}$ of sleep deprivation, when the increase in total body energy metabolism became apparent but well before the eventual deterioration of health occurred, local rates of cerebral glucose utilization $\left(1 \mathrm{CMR} \mathrm{R}_{\mathrm{glc}}\right)$ were determined with the quantitative autoradiographic $2-{ }^{14} \mathrm{C}$-deoxyglucose $\left(2-{ }^{14} \mathrm{C}-\mathrm{DG}\right)$ method (Sokoloff et al., 1977) in both the paired sleep-deprived and yoked-control rats. To stabilize blood glucose concentrations during the measurement of $1 \mathrm{CMR}_{\mathrm{glc}}$, the rats were fasted $12-$ $17 \mathrm{hr}$ prior to the procedure. The rats remained in the experimental apparatus under sleep deprivation and yoked-control conditions throughout the procedure. Mean arterial blood pressure, $\mathrm{pCO}_{2}, \mathrm{pO}_{2}$, $\mathrm{pH}$, and hematocrit and arterial plasma glucose concentration were measured immediately before the procedure was initiated by the intravenous injection of a pulse of $120 \mu \mathrm{Ci} / \mathrm{kg}$ of 2-deoxy-D-1-14 C-glucose (45-55 $\mathrm{mCi} / \mathrm{mmol}$ specific activity; New England Nuclear-DuPont, Boston, MA). Timed arterial blood samples $(60 \mu \mathrm{l})$ were then drawn during the subsequent $45 \mathrm{~min}$ period and immediately centrifuged to separate the plasma for subsequent measurement of plasma $2-{ }^{14} \mathrm{C}-\mathrm{DG}$ and glucose concentrations. To minimize hypovolemia, the blood was replaced by intravenous injections of heparinized saline at convenient times during the sampling schedule. Mean arterial pressure was monitored intermittently with an air-damped mercury manometer attached to the arterial catheter. Blood samples for measurement of hematocrit were collected in capillary tubes (Strumia type, Sherwood Medical Industries, St. Louis, MO) and centrifuged at $10,000 \mathrm{rpm}$ for $1 \mathrm{~min}$. Blood for measurements of $\mathrm{pH}, \mathrm{pCO}_{2}$, and $\mathrm{pO}_{2}$ was collected in $50 \mu 1$ microcapillary tubes (Corning Medical, Medfield, MA), capped, and analyzed within $10 \mathrm{~min}$. At the end of the $45 \mathrm{~min}$ period, the rats were killed by an intravenous injection of $150 \mathrm{mg} / \mathrm{kg}$ of sodium pentobarbital, and their brains were immediately removed and frozen in 2-methylbutane that had been cooled to $-40^{\circ} \mathrm{C}$. Necropsy examinations were then performed.

The brain sections werc cut coronally into $20-\mu \mathrm{m}$-thick sections in a cryostat maintained at $-22^{\circ} \mathrm{C}$, thaw mounted on glass coverslips, dried at $60^{\circ} \mathrm{C}$ on a hot plate, and autoradiographed together with a set of calibrated ${ }^{14} \mathrm{C}$-methylmethacrylate standards as previously described 
Table 1. Percentage of time in wakefulness and sleep stages in rats in which $\mathrm{ICMR}_{\mathrm{glc}}$ was measured

\begin{tabular}{|c|c|c|c|c|c|c|}
\hline \multirow[b]{3}{*}{ Group/condition } & \multirow[b]{3}{*}{$\begin{array}{l}\text { Wakefulness } \\
\text { (total) }\end{array}$} & \multicolumn{5}{|l|}{ Sleep } \\
\hline & & \multirow[b]{2}{*}{ Total } & \multicolumn{3}{|c|}{ Non-rapid eye movement } & \multirow[b]{2}{*}{$\begin{array}{l}\text { Paradoxical } \\
\text { (total) }\end{array}$} \\
\hline & & & Total & $\begin{array}{l}\text { High } \\
\text { amplitude }\end{array}$ & $\begin{array}{l}\text { Low } \\
\text { amplitude }\end{array}$ & \\
\hline \multicolumn{7}{|c|}{ Sleep deprived $(6)$} \\
\hline Baseline & $45.9 \pm 6.1$ & $54.1 \pm 6.1$ & $48.8 \pm 5.6$ & $44.8 \pm 5.5$ & $4.0 \pm 0.3$ & $5.3 \pm 0.9$ \\
\hline Experimental & $90.3 \pm 4.0$ & $9.7 \pm 4.0$ & $9.3 \pm 3.9$ & $5.1 \pm 3.9$ & $4.2 \pm 0.1$ & $0.4 \pm 0.2$ \\
\hline \multicolumn{7}{|l|}{ Yoked control (6) } \\
\hline Baseline & $47.5 \pm 6.2$ & $52.5 \pm 6.2$ & $46.6 \pm 5.0$ & $42.6 \pm 5.0$ & $4.0 \pm 0.2$ & $5.9 \pm 1.5$ \\
\hline Experimental & $58.3 \pm 2.2$ & $41.7 \pm 2.2$ & $38.6 \pm 2.5$ & $34.5 \pm 2.7$ & $4.1 \pm 0.5$ & $3.1 \pm 0.6$ \\
\hline
\end{tabular}

Values are means \pm SD for the number of rats indicated in parentheses.

(Sokoloff et al., 1977). Local ${ }^{14} \mathrm{C}$ concentrations in the cerebral tissues were determined from the autoradiograms of the brain sections and the standards by quantitative densitometry with a computerized imageprocessing system (MCID, Imaging Research, Inc., St. Catharines, Ontario, Canada). Sixty brain structures that varied in function, anatomical location, and metabolic activity were selected for examination. For each structure densitometric measurements were made bilaterally in at least six brain sections per rat, except for an occasional instance when the representation of the region across six sections was technically defective because of too small a size or distortion by artifact; in those cases, measurements from fewer than six sections were used. In addition, there was one brain of a yoked-control rat wherein the hippocampal pyramidal cell layer and dentate gyrus on one side had abnormally high rates of glucose utilization for reasons that are not clear. The values for other brain regions were within the normal range, and the abnormal area was excluded in computations of glucose utilization. Structures were identified from the autoradiograms according to the stereotaxic atlas of the rat brain of Paxinos and Watson (1986).

Local cerebral glucose utilization was calculated from the time courses of the arterial plasma $2-{ }^{14} \mathrm{C}-\mathrm{DG}$ and glucose concentrations and the tissue ${ }^{14} \mathrm{C}$ concentrations by the operational equation of the method and the rate constants for normal rats (Sokoloff et al., 1977). Although nearly all the plasma glucose concentrations were greater than $5 \mathrm{~mm}$, the lumped constant was adjusted for the effects of mild hypoglycemia according to the data of Suda et al. (1990). The average rate of glucose utilization in the brain as a whole, appropriately weighted for the relative sizes of its components, was determined as previously described (Goochee et al., 1980).

Chemical assays in blood and plasma. Arterial blood $\mathrm{pH}, \mathrm{pCO}_{2}$, and $\mathrm{pO}_{2}$ were measured with a Corning $158 \mathrm{pH}$ Blood Gas Analyzer (Corning Ltd., Halstead, Essex, UK). Plasma $2-{ }^{14} \mathrm{C}-\mathrm{DG}$ concentrations were determined by liquid scintillation counting with external standardization (Packard Instrument Co., Model 2000CA, Downers Grove, IL). Plasma glucose concentrations were assayed with a Beckman Glucose Analyzer 2 (Beckman Instruments, Fullerton, CA). Arterial plasma D- $\beta$-hydroxybutyrate $(\beta-\mathrm{OHB})$ concentrations were determined by enzymatic spectrophotometric assay (Sigma kit 310-UV, Sigma, St. Louis, MO) in five of the six experiments (experimental pairs 2-6).

Comparison of cerebral metabolic rate and brain temperature. Because measurement of deep brain temperature requires insertion of probes that could alter $\mathbf{l C M R}_{\mathrm{glc}}$, comparative data on brain temperature were obtained from six other pairs of sleep-deprived and yoked-control rats that were matched for age and weight $[25 \pm 2( \pm \mathrm{SD})$ weeks old; 429 $\pm 30( \pm \mathrm{SD}) \mathrm{gm}]$ to those in which $\mathrm{ICMR}_{\mathrm{glc}}$ was determined. They were fed a purified diet of normal composition and were not catheterized, but were otherwise monitored and treated like the other pairs. Small $10 \mathrm{~K} \Omega$ bead thermistors (Thermometrics, Edison, NJ) were customized by encapsulation in polyethylene tubing $(0.96 \mathrm{~mm} \mathrm{o.d}$.) with a wire to add rigidity and with the sensor bead left exposed. This assembly was thinly coated with paraffin (Mini-Mitter Co., Inc., Sunriver, OR) to increase its resistance to immersion. The thermistor was implanted into the pontine region of the brain according to the following stereotaxic coordinates: zero at the junction of the lambda and central sutures, 1.4 $\mathrm{mm}$ anterior, $0.4 \mathrm{~mm}$ lateral, and $8 \mathrm{~mm}$ deep. The thermistor leads were wired to the electrode head plug assembly. Resistance readings were converted to temperature by means of a curve fit to a two-point calibration at $25^{\circ} \mathrm{C}$ and $37^{\circ} \mathrm{C}$ supplied by the manufacturer. The same Barrows telemetric transmitter device described above was implanted into the peritoneal cavity. As in the rats studied with $2-{ }^{14} \mathrm{C}-\mathrm{DG}$, only epochs of wakefulness were used to compare temperature changes in sleep-deprived and yoked-control rats.

Data analysis. Chronological data, such as comparisons of brain and core temperature in the sleep-deprived and yoked-control groups, were analyzed with a three-factor repeated-measures analysis of variance if the data were paired and a two-factor repeated-measures analysis of variance if the data were not paired (Kirk, 1968). Values of $1 \mathrm{CMR}_{\mathrm{glc}}$ in sleep-deprived and yoked-control rats were compared by means of Student's $t$ tests for paired comparisons. The application of Bonferroni correction for multiple comparisons (Miller, 1966) requires a $p<0.00086$ for statistical significance at the $95 \%$ confidence level with the analysis of 60 regions. This very conservative approach was not applied in our survey of the brain.

\section{Results}

\section{Degree of sleep deprivation}

Sleep was severely restricted in sleep-deprived rats and much less so in the yoked-control rats. During the 11-12 d experimental period, sleep-deprived rats were awake $90 \pm 4 \%( \pm \mathrm{SD})$ of total time (Table 1), whereas wakefulness in the yoked-control rats increased from a normal level of $47 \pm 6 \%( \pm \mathrm{SD})$ to $58 \pm$ $2 \%( \pm \mathrm{SD})$ of total time.

\section{Physiological variables}

The sleep-deprived rats exhibited evidence of a marked total body hypercatabolism compared to the yoked controls. In the $24 \mathrm{hr}$ preceding the withdrawal of food, the period of measurement closest to the time of determination of $1 \mathrm{CMR}_{\mathrm{glc}}$, the sleepdeprived rats had increased their food intake by $108 \pm 27 \%$ $( \pm$ SEM $)$ and yet lost $4 \pm 1 \%( \pm$ SEM $)$ of their body weight from baseline values, whereas yoked-control rats increased their food intake $58 \pm 23 \%( \pm$ SEM) with an insignificant change in body weight of $-1 \pm 1 \%( \pm$ SEM) of baseline values (Fig. 1). The difference in the kilocalories consumed by the two groups during this period was statistically significant $(p<0.05)$; the losses in body weight did not differ significantly.

Mean arterial blood pressure was mildly but significantly elevated in sleep-deprived rats compared with that of the yoked controls (Table 2). At the beginning of the $2-{ }^{14} \mathrm{C}-\mathrm{DG}$ procedure, arterial plasma glucose concentration was $7 \%$ higher $(p<0.02)$ in the sleep-deprived rats than in the yoked controls, but this difference disappeared during the $45 \mathrm{~min}$ period of the $1 \mathrm{CMR}_{\mathrm{glc}}$ determination. Arterial $\mathrm{pH}, \mathrm{pO}_{2}$ and $\mathrm{pCO}_{2}$ were essentially the same in both groups. The values for hematocrit were lower than normal in both groups, but this is not unusual in chronically 


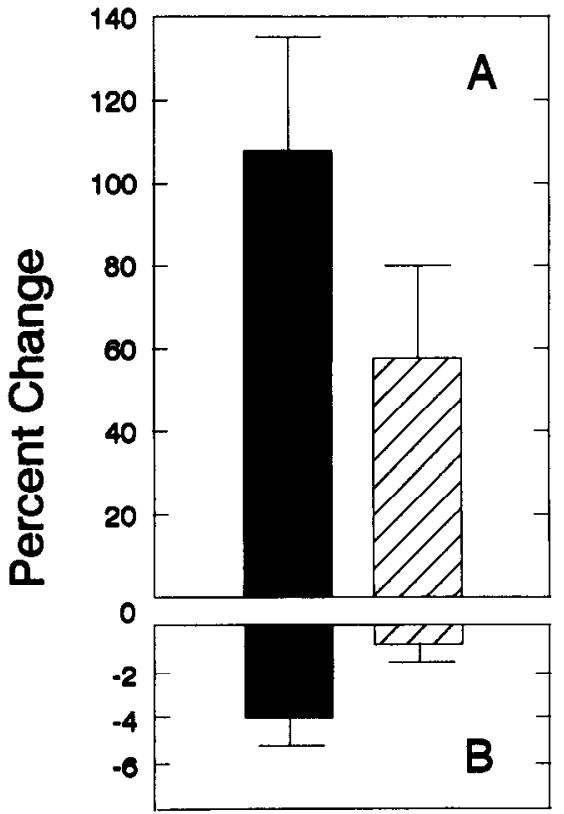

Figure 1. Mean percentage change $( \pm \mathrm{SEM})$ from baseline in caloric intake $(A)$ and body weight $(B)$ for sleep-deprived $(n=6$; solid bars) and yoked-control $(n=6$; hatched bars) rats during the last $24 \mathrm{~h}$ period prior to the fast before the $2-{ }^{14} \mathrm{C}-\mathrm{DG}$ procedure.

catheterized rats under these experimental conditions (C. Everson, unpublished observations).

\section{Local cerebral glucose utilization}

Of the 60 gray and white structures examined, $\mathrm{CCMR}_{\mathrm{glc}}$ in 42 structures was unchanged (e.g., within $\pm 6 \%$ ) in the sleep-deprived rats from the corresponding values in the yoked controls (Table 3). In 18 structures, however, $\mathrm{lCMR}_{\mathrm{glc}}$ was statistically significantly $(p<0.05)$ lower in the sleep-deprived rats than in the yoked controls. The structures with the most pronounced reductions were concentrated mainly in the hypothalamus and thalamus and, to a lesser extent, in the limbic system (Fig. 2). There were few deviations from the control values in the cortex, mesencephalon, and pons and no significant changes in the medulla. The average rate of glucose utilization in the brain as a whole did not differ statistically significantly between the two groups (i.e., mean $\pm \mathrm{SEM}, 70 \pm 2 \mu \mathrm{mol} / 100 \mathrm{gm} / \mathrm{min}$ in sleepdeprived rats compared to $76 \pm 2 \mu \mathrm{mol} / 100 \mathrm{gm} / \mathrm{min}$ in yokedcontrol rats).

\section{Plasma ketone body levels}

The introduction of the high-fat, high-caloric diet at the onset of the baseline period to minimize weight loss during the experimental period raised the $\beta$-OHB concentration in plasma from a prebaseline level of $0.25 \pm 0.05( \pm$ SEM) $\mu \mathrm{mol} / \mathrm{ml}$ determined in a subset of seven rats to a baseline level of $0.67 \pm$ $0.05( \pm \mathrm{SEM} ; n=10) \mu \mathrm{mol} / \mathrm{ml}$. Plasma $\beta-\mathrm{OHB}$ levels did not, however, change appreciably from the baseline levels during the experimental period of sleep deprivation (Fig. 3), even though the hyperphagia of the sleep-deprived rats was presumably associated with increased $\beta$-OHB production. In fact, the plasma $\beta$-OHB concentration in sleep-deprived rats on experimental day 10 , the day before the determination of $1 C^{-M R_{\text {glc }} \text {, was not }}$ significantly different from that of the yoked controls. Also, in experiments 5 and 6 , arterial plasma $\beta$-OHB levels were measured on experimental day 11 immediately prior to the determination of $1 \mathrm{CMR}_{\mathrm{elc}}$ after the rats had been fasted for $12-17 \mathrm{hr}$; the values were 0.87 and $0.52 \mu \mathrm{mol} / \mathrm{ml}$ in the sleep-deprived rats and 0.41 and $0.73 \mu \mathrm{mol} / \mathrm{ml}$ in the paired yoked controls, respectively.

\section{Brain and core temperatures}

There was no significant difference in core temperature between the sleep-deprived rats in which brain temperature was measured and those in which $\mathrm{ICMR}_{\mathrm{glc}}$ was measured (Fig. 4). Brain temperature became mildly elevated relative to core temperature in sleep-deprived rats (Fig. 4), a result similar to that reported previously (Obermeyer et al., 1991). The average daily difference between each rat's brain and core temperature increased significantly more in the sleep-deprived rats than in their yoked-control partners [group by time interaction: $F(10,50)=$ $2.12, p<0.05]$. Therefore, at the time of the measurement of $\mathrm{lCMR}_{\mathrm{gl}}$, body temperature was at a baseline level and brain temperature in sleep-deprived rats was mildly elevated relative to body temperature.

\section{Discussion}

The present results demonstrate a dissociation between the energy metabolism of the body and of the brain during sleep deprivation. Prolonged sleep deprivation resulted in increased whole-body energy expenditure, whereas glucose utilization was either normal or reduced in the various structural components of the brain compared to their values in yoked-control rats. The greatest reductions were found in the hypothalamus, thalamus, and limbic system; no structures in the medulla and few in the mesencephalon and pons were affected.

Utilization of alternative substrates by the brain was a concern

\begin{tabular}{lcc}
\hline \multicolumn{2}{l}{ Table 2. Physiological variables in sleep-deprived and yoked-control rats } \\
Variable & Yoked control & Sleep deprived \\
\hline Arterial plasma glucose concentration $(\mathrm{mg} / \mathrm{dl})$ & $99 \pm 3$ & $106 \pm 2^{* *}$ \\
Mean arterial blood pressure $(\mathrm{mm} \mathrm{Hg})$ & $104 \pm 2$ & $116 \pm 5^{*}$ \\
Arterial blood $\mathrm{pO}_{2}(\mathrm{~mm} \mathrm{Hg})$ & $85 \pm 2$ & $82 \pm 2$ \\
Arterial blood pCO $(\mathrm{mm} \mathrm{Hg})$ & $34 \pm 1$ & $31 \pm 1$ \\
Arterial blood pH & $7.49 \pm 0.01$ & $7.48 \pm 0.01$ \\
Arterial hematocrit $(\%)$ & $38 \pm 1$ & $36 \pm 1$ \\
\hline
\end{tabular}

\footnotetext{
Values are means \pm SEM, six rats per group.

${ }^{*} p<0.05$, two-tailed Student's $t$ test for paired samples.

** $p<0.02$, two-tailed Student's $t$ test for paired samples.
} 


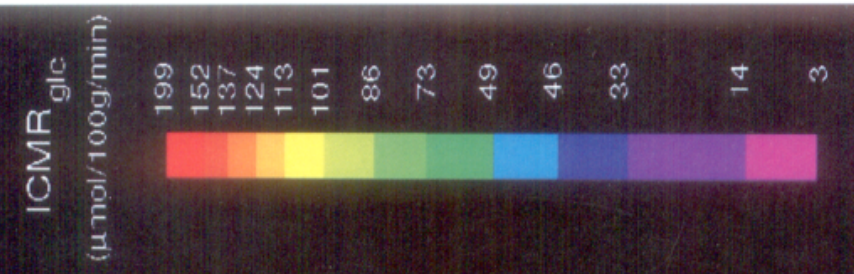

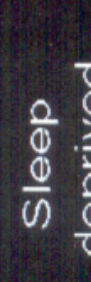
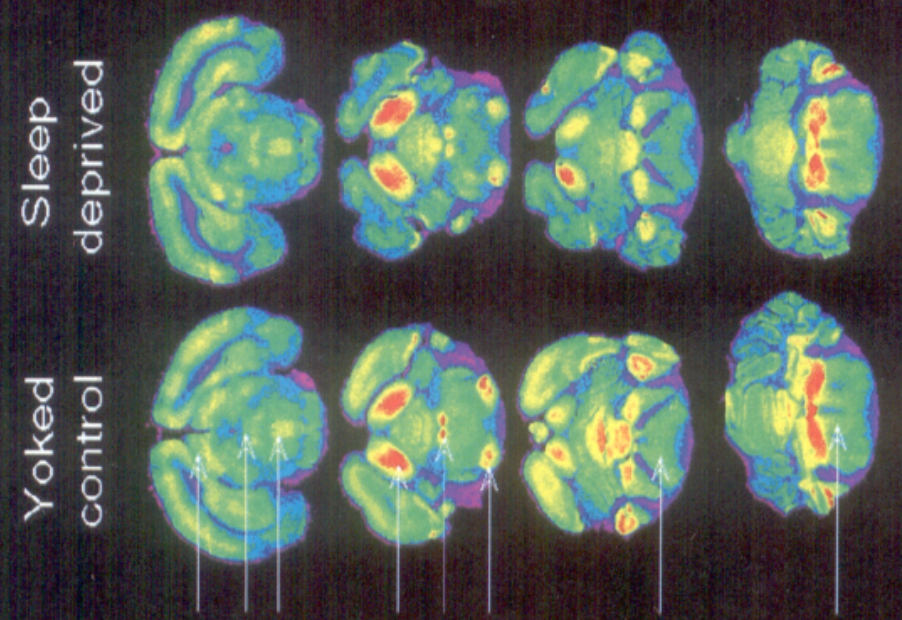
O) $\llbracket$

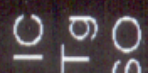
U
50

$\frac{0}{2}$
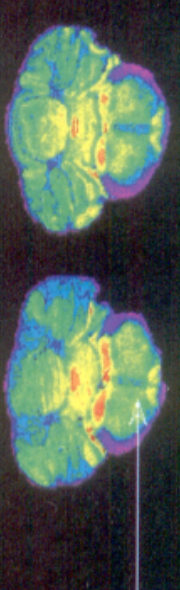

ज

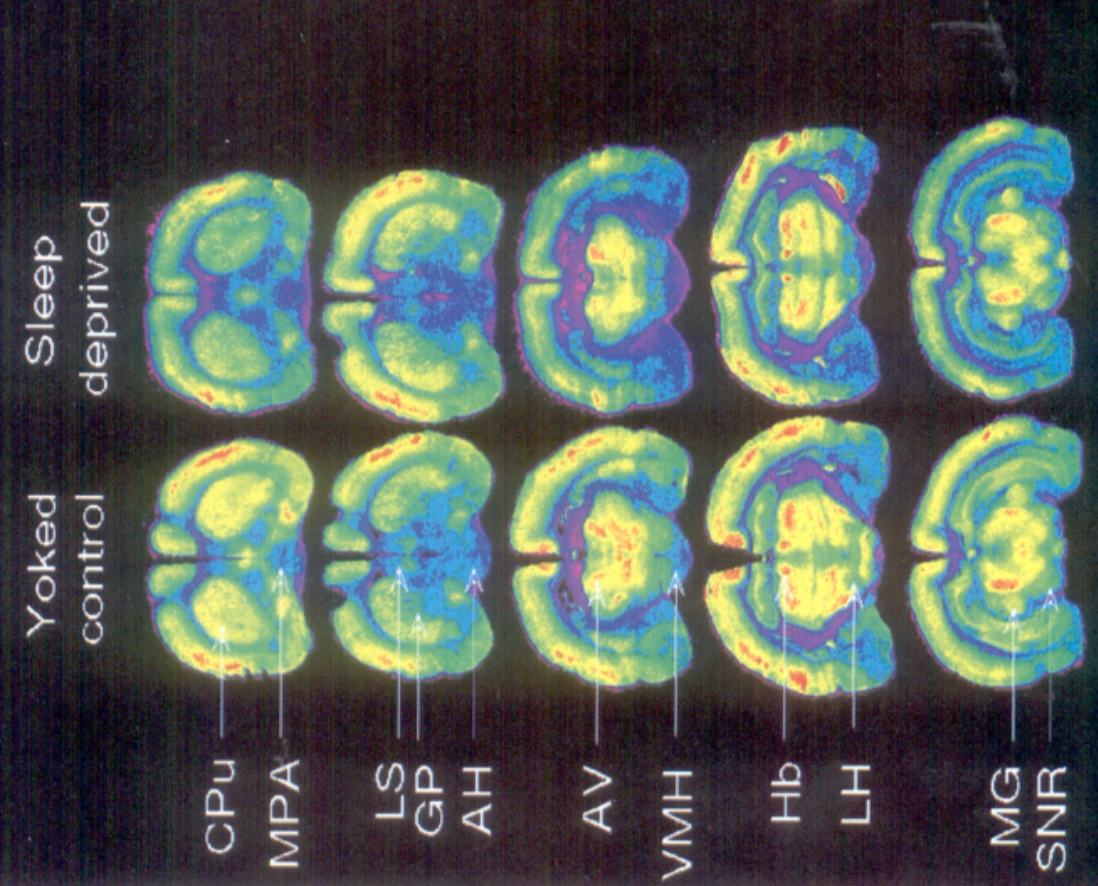

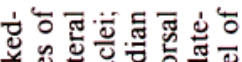

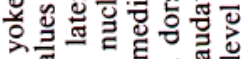

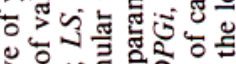

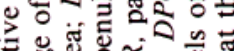

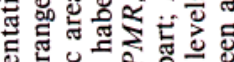

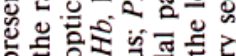

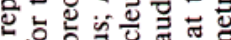

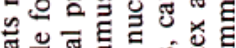

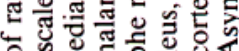

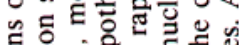

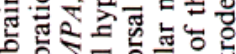

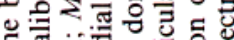
क्ष 드 응 的 过

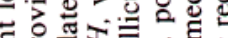

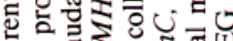

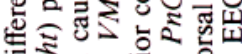

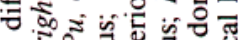

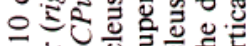

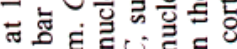

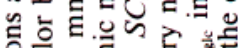
的的

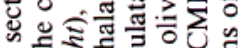

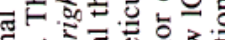

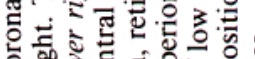
웅. o

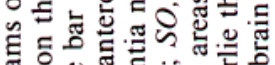
颔. 음 议 क्ष 드응

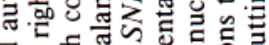
诃

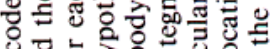

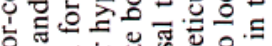

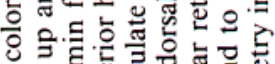

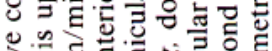

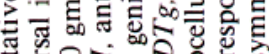

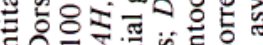

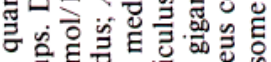

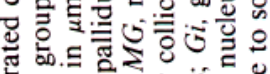

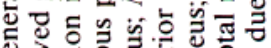

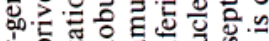

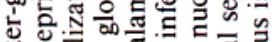

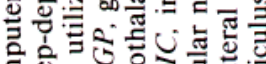

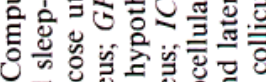

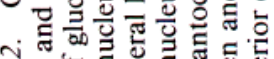

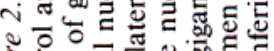

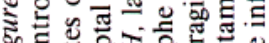

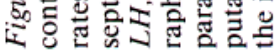


Table 3. Effects of prolonged sleep deprivation on local rates of cerebral glucose utilization ( $\mu \mathrm{mol} / 100$ $\mathrm{gm} / \mathbf{m i n}$ )

\begin{tabular}{|c|c|c|c|}
\hline Structure & Yoked control & Sleep deprived & $\%$ Effect $^{a}$ \\
\hline \multicolumn{4}{|l|}{ Cerebral cortex } \\
\hline Frontal cortex, areas 1 and 2 & $89 \pm 3$ & $87 \pm 5$ & -1 \\
\hline Piriform cortex & $128 \pm 4$ & $118 \pm 5$ & -7 \\
\hline Sensorimotor cortex & $100 \pm 3$ & $86 \pm 4$ & -14 \\
\hline Parietal cortex & $110 \pm 4$ & $99 \pm 7$ & -9 \\
\hline Occipital cortex, area 1 & $99 \pm 4$ & $86 \pm 3$ & $-12^{*}$ \\
\hline \multicolumn{4}{|l|}{ Basal ganglia } \\
\hline Caudate-putamen & $108 \pm 7$ & $93 \pm 3$ & -13 \\
\hline Globus pallidus & $62 \pm 2$ & $58 \pm 2$ & -6 \\
\hline \multicolumn{4}{|l|}{ Basal forebrain and limbic system } \\
\hline Accumbens $\mathbf{n}$. & $85 \pm 6$ & $74 \pm 6$ & -12 \\
\hline N. horizontal limb diagonal band & $107 \pm 5$ & $100 \pm 5$ & -5 \\
\hline Magnocellular preoptic $n$. & $108 \pm 5$ & $98 \pm 5$ & -8 \\
\hline Lateral septal $\mathrm{n}$. & $56 \pm 3$ & $49 \pm 2$ & $-12^{*}$ \\
\hline Central amygdaloid $n$. & $45 \pm 1$ & $40 \pm 2$ & $-12 * *$ \\
\hline Dentate gyrus & $66 \pm 2$ & $61 \pm 3$ & -8 \\
\hline Cortical amygdaloid n., posteromedial & $55 \pm 2$ & $44 \pm 2$ & $-19^{* * *}$ \\
\hline Mammillary body & $113 \pm 5$ & $117 \pm 7$ & +5 \\
\hline Hippocampus-Ammon's horn & $74 \pm 3$ & $63 \pm 3$ & $-14^{*}$ \\
\hline \multicolumn{4}{|l|}{ Hypothalamus } \\
\hline Medial preoptic area & $42 \pm 2$ & $36 \pm 3$ & $-15^{* *}$ \\
\hline Lateral preoptic area & $73 \pm 3$ & $64 \pm 2$ & $-12^{* * * *}$ \\
\hline Suprachiasmatic $\mathrm{n}$. & $46 \pm 2$ & $40 \pm 2$ & -13 \\
\hline Anterior hypothalamic area & $46 \pm 2$ & $38 \pm 3$ & $-17^{* *}$ \\
\hline Ventromedial hypothalamic $n$. & $39 \pm 2$ & $31 \pm 2$ & $-20^{* * * *}$ \\
\hline Dorsomedial hypothalamic $\mathrm{n}$. & $58 \pm 4$ & $54 \pm 3$ & -6 \\
\hline Arcuate hypothalamic $n$ & $39 \pm 2$ & $33 \pm 4$ & -15 \\
\hline Posterior hypothalamic area & $68 \pm 4$ & $56 \pm 2$ & $-17^{* * *}$ \\
\hline Lateral hypothalamic area & $64 \pm 3$ & $64 \pm 2$ & 0 \\
\hline \multicolumn{4}{|l|}{ Thalamus } \\
\hline Anterodorsal thalamic $\mathbf{n}$. & $93 \pm 4$ & $83 \pm 1$ & -10 \\
\hline \multicolumn{4}{|l|}{ Anteroventral thalamic n., } \\
\hline Medial forebrain bundle & $63 \pm 3$ & $55 \pm 2$ & $-11^{* * *}$ \\
\hline \multicolumn{4}{|l|}{ Mediodorsal thalamic $n}$. \\
\hline Medial habenular $\mathrm{n}$. & $72 \pm 1$ & $62 \pm 2$ & $-14^{* *}$ \\
\hline Lateral habenular n., medial & $102 \pm 3$ & $89 \pm 2$ & $-13^{* * *}$ \\
\hline Lateral habenular n., lateral & $142 \pm 7$ & $138 \pm 5$ & -1 \\
\hline Dorsal lateral geniculate $\mathrm{n}$. & $73 \pm 2$ & $64 \pm 2$ & $-12^{* *}$ \\
\hline Medial geniculate body & $103 \pm 5^{b}$ & $95 \pm 3$ & $-6^{h}$ \\
\hline \multicolumn{4}{|l|}{ Mesencephalon } \\
\hline Substantia nigra, reticulata & $59 \pm 3$ & $60 \pm 4$ & +3 \\
\hline Red nucleus & $94 \pm 6$ & $93 \pm 5$ & +1 \\
\hline Superior colliculus & $94 \pm 4$ & $88 \pm 2$ & -5 \\
\hline Central gray & $66 \pm 2$ & $56 \pm 1$ & $-15^{* *}$ \\
\hline Oculomotor $\mathrm{n}$. & $123 \pm 9$ & $122 \pm 7$ & +3 \\
\hline Inferior colliculus ${ }^{h}$ & $123 \pm 5$ & $123 \pm 4$ & +1 \\
\hline Dorsal raphe $\mathrm{n}$. & $78 \pm 2$ & $78 \pm 7$ & 0 \\
\hline \multicolumn{4}{|l|}{ Pons } \\
\hline Pedunculopontine tegmental $\mathrm{n}$. & $69 \pm 1$ & $66 \pm 3$ & -4 \\
\hline Median and paramedian raphe & $104 \pm 4$ & $94 \pm 2$ & -10 \\
\hline Ventral tegmental $n$ & $123 \pm 5$ & $108 \pm 3$ & -11 \\
\hline Superior olivary $n$ & $113 \pm 3$ & $104 \pm 2$ & $-7^{*}$ \\
\hline Laterodorsal tegmental $n$. $^{*}$ & $98 \pm 2$ & $92 \pm 4$ & -6 \\
\hline Dorsal tegmental $\mathrm{n}$. & $141 \pm 7$ & $124 \pm 3$ & $-11^{*}$ \\
\hline Pontine reticular $n$., caudal part & $70 \pm 2$ & $69 \pm 4$ & -1 \\
\hline
\end{tabular}




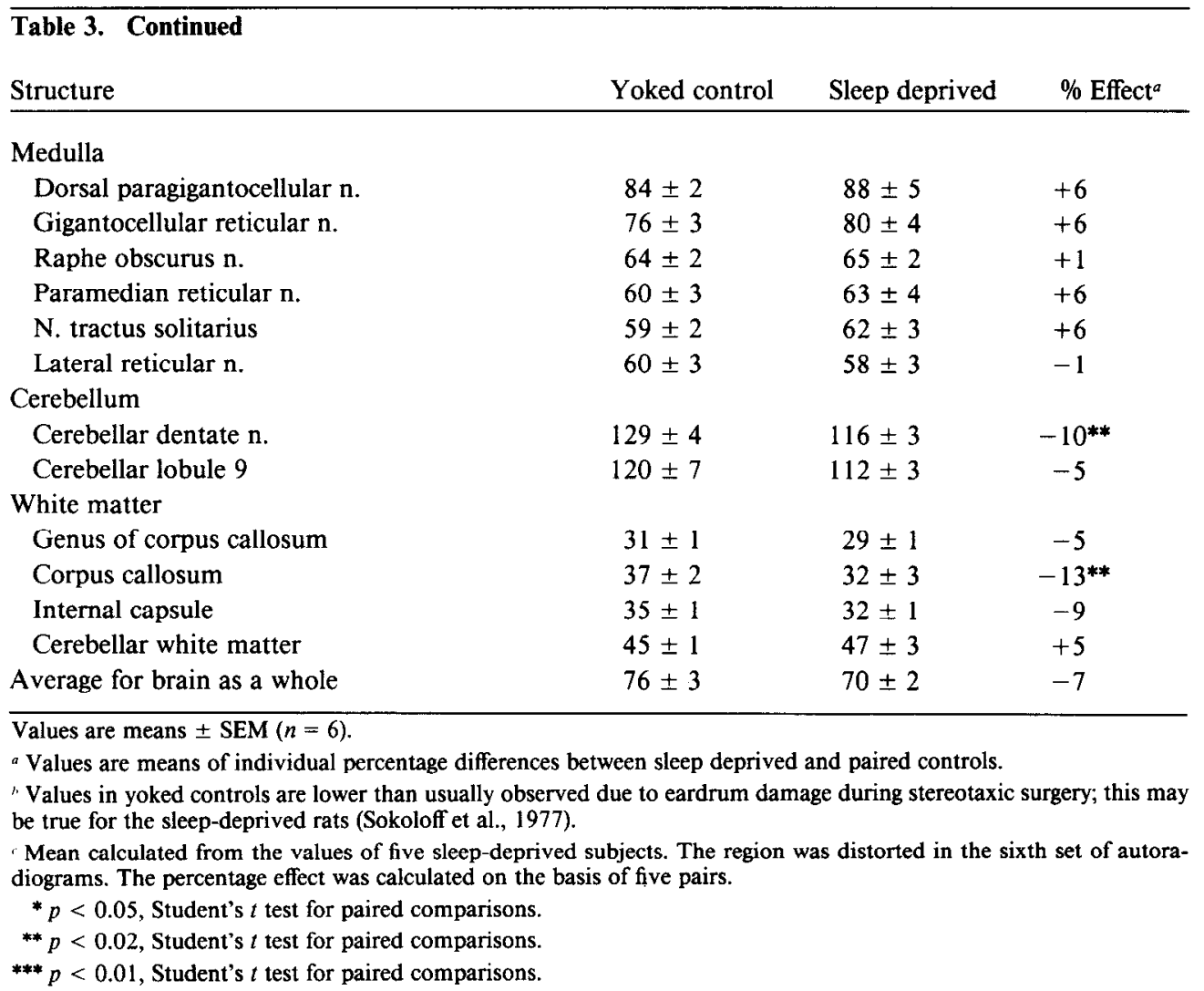

because the hyperphagia of a fat-laden diet and the evidence of increased body metabolism in the sleep-deprived rats could lead to ketosis. Fat feeding raises blood levels of the ketone bodies, acetoacetate, and $D-\beta$-hydroxybutyrate, which can replace glucose as the brain's energy source in proportion to their levels in the blood (Hawkins et al., 1971; Krebs et al., 1971; Robinson and Williamson, 1980). In the present study, plasma levels of $\beta$-OHB were somewhat above normal in both the sleep-deprived and the yoked-control rats but were not statistically significantly different from each other. Furthermore, the slight degree of ketosis was not sufficient to depress the rate of cerebral glucose utilization; average glucose utilization in the brain as a whole was $76 \pm 3( \pm$ SEM $)$ and $70 \pm 2( \pm$ SEM $) \mu \mathrm{mol} / 100 \mathrm{gm} / \mathrm{min}$ in the yoked-control $(n=6)$ and sleep-deprived rats $(n=6)$, respectively, compared to a range of $69 \pm 3(n=10)$ to $77 \pm 2$ $(n=4) \mu \mathrm{mol} / 100 \mathrm{gm} / \mathrm{min}$ reported in unanesthetized rats of approximately the same age of 4-6 months (Sokoloff, 1985; Smith et al., 1980, respectively). The differences in $\mathrm{CMR}_{\mathrm{glc}}$ in the sleep-deprived and yoked-control rats, therefore, cannot be ascribed to a difference in the degree of ketosis.

In view of the marked elevation of total body metabolism in prolonged sleep deprivation, increases in functional and/or metabolic activity in some regions of the brain might have been expected. The absence of such increases is similar to the situation in clinical hyperthyroidism in which, despite marked increases in total body basal metabolic rate, cerebral oxygen consumption remains unchanged (Scheinberg, 1950; Sokoloff et al., 1953: Sensenbach et al., 1954).

Increased functional activity in the nervous system is generally accompanied by increased glucose utilization in the activated regions, and metabolic activation can be used to map regions with altered functional activity (Sokoloff, 1977, 1985).
Hyperarousal, distress, and hypervigilance can cause sleep deprivation and have become closely associated with it. There have been suggestions that these behavioral conditions are responsible for sympathetic activation (Pilchcr ct al., 1990) and the increases in total body metabolism and brain temperature that these animals exhibit. If so, one would expect functionally activated regions in the brain. The absence of metabolic acti-

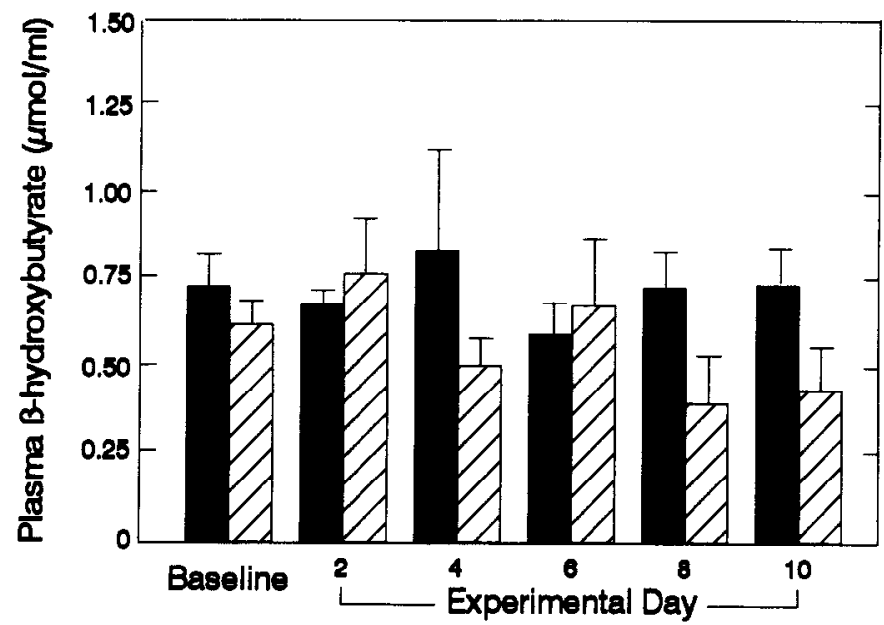

Figure 3. Mean plasma levels of $\mathrm{D}-\beta$-hydroxybutyrate $( \pm$ SEM) in sleepdeprived $(n=5$; solid bars) and yoked-control $(n=5$; hatched bars) groups during baseline and every other day throughout the experimental period prior to the $2-{ }^{-14} \mathrm{C}$-DG procedure. Despite the likelihood of increased production in sleep-deprived rats because of high food intake, and no net body weight gain, $\mathrm{D}-\beta$-hydroxybutyrate concentration did not increase. 


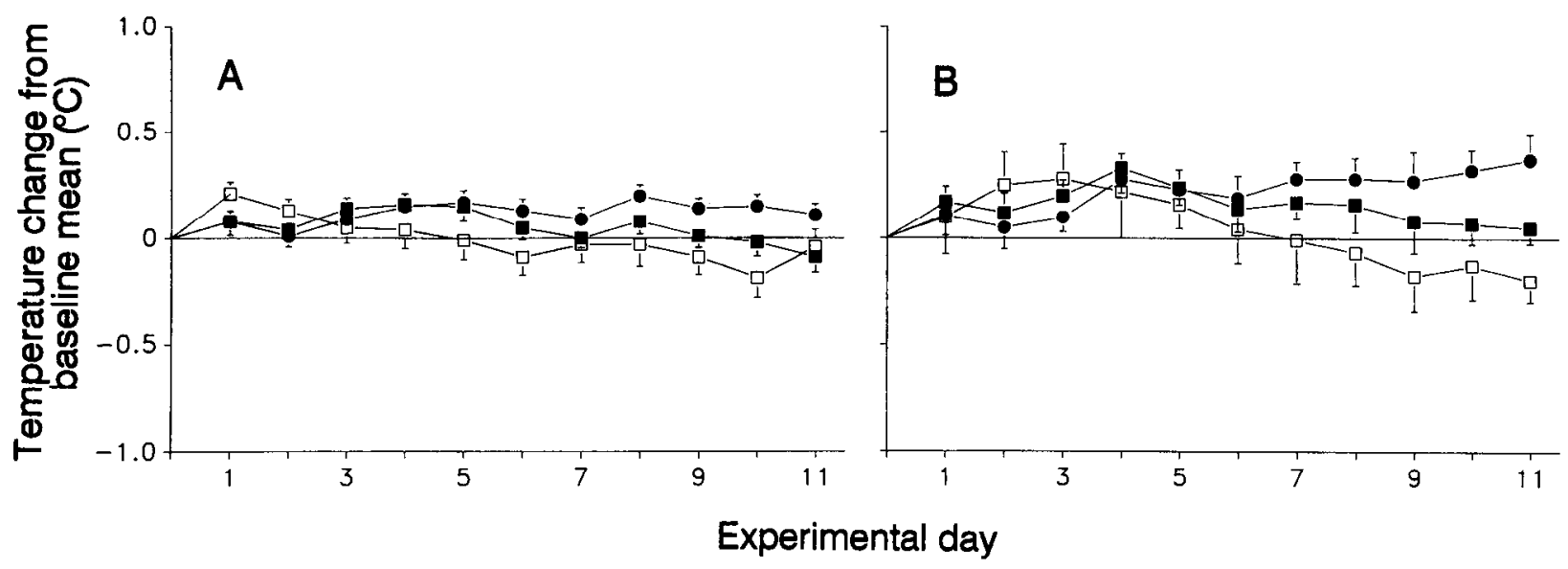

Figure 4. Mean daily temperature change $( \pm$ SEM) from the baseline average in yoked-control $(A)$ and sleep-deprived $(B)$ rats across experimental days. Core temperatures of groups in which local rates of cerebral energy metabolism were measured $[\square ; n=6$ yokcd-control rats and $n=5$ sleepdeprived rats (data from the sixth rat is missing due to failure of the transmitter)] are shown with the core temperatures ( $\square$ ) from six similarly treated rat pairs in which brain temperature $(\boldsymbol{O})$ was also recorded.

vation in any structure of the brain in sleep-deprived rats casts doubt on the validity of these speculations. Nor was there evidence that energy metabolism is lowered to approach a sleeplike state in the cerebrum because during slow-wave sleep cerebral metabolism is decreased everywhere in the brain by approximately $30 \%$ (Kennedy et al., 1982).

Although the decreases in local cerebral metabolic rate in the sleep-deprived rats were only moderate, the constellation of structures affected may reflect complex interactions among related regions and the functions they serve. Most of the affected regions were anterior to the mesencephalon and tended to be concentrated in the hypothalamus, thalamus, and limbic system. Thesc regions are associated with sleep, feeding, thermoregulation, and endocrine processes. In contrast, the medulla and sites associated with arousal, respiratory function, and other basic functions that are neither adaptable nor dispensable were not particularly affected. Interestingly, these latter areas have been purported not to "need" sleep (Moruzzi, 1966).

There may, however, be associations between structures in which metabolism was reduced and some of the systemic effects observed in the sleep-deprived rats, for example, low plasma thyroxine levels, hyperphagia, and indications of impaired thermoregulatory and inflammatory responses. The preoptic and anterior areas of the hypothalamus, which were affected by sleep deprivation in the present study, are considered to be major foci for sleep regulation, thermoregulation (Szymusiak et al., 1991), and host defense responses (Blatteis, 1990; Shibata, 1990; Hori et al., 1991). Evidence for interdependent relationships among these processes have been found with many experimental paradigms. For example, experimental damage to the preoptic/ anterior hypothalamus in cats results in long-lasting reductions in sleep (up to 7 weeks) and an impaired ability to maintain body temperature in warm environments (Szymusiak et al., 1991). Medial preoptic lesions in rats alter autonomic thermoregulatory reflexes, but the ability to defend body temperature by escaping heat or cold is preserved (Szymusiak et al., 1985). As sleep deprivation is prolonged, rats develop hypothermia, while whole-body energy metabolism continues to increase, indicating heat loss and problems with thermoregulation (Obermeyer et al., 1991), but the behavioral response to choose increasingly warmer ambient temperatures remains strong (Prete et al., 1991). Also, sleep-deprived rats eventually develop lifethreatening, opportunistic infections that are not accompanied by fever or significant tissue responses compared with those typically found in most infectious disease states (Everson, 1993). This raises questions about the sleep-deprived rat's ability to mount a fever. The hypothalamus has important roles in both thermoregulation and production of fever in response to challenges to host defenses.

The loci of the changes in $1 \mathrm{CMR}_{\mathrm{glc}}$ in the hypothalamus are anatomically consistent with the sleep-deprived rat's marked hyperphagia. Experimental lesions in and around the ventromedial hypothalamus (VMH) in rats cause striking hyperphagia (Grossman, 1976; Sclafani, 1976). Although rats with such lesions develop gross obesity, which is in contrast with the inability of the sleep-deprived rat to gain weight, the VMH-lesion syndrome is the only other known condition that produces the magnitude of voluntary eating observed in the sleep-deprived rat. Therefore, it is noteworthy that the VMH was one of the structures most robustly affected in the present experiment, whereas the lateral hypothalamus, lesions of which are known to cause aphagia and to lower set point for body weight, remained unaffected in the sleep-deprived rats.

Changes in the profile of thyroid hormones in the sleep-deprived rat have suggested that there might be an impairment in a hypothalamic regulating mechanism. As sleep deprivation progresses, thyroxine $\left(\mathrm{T}_{4}\right)$ concentrations in plasma decrease, eventually to undetectable levels in some cases (Bergmann et al., 1989b). Low plasma $T_{4}$ concentration is a potent stimulator of thyroid-stimulating hormone (TSH) release from the antcrior pituitary, which in turn stimulates thyroxine production (Utiger, 1987). Despite low plasma $T_{4}$ concentrations in sleep-deprived rats, TSH levels are not augmented. Stimulation of the pituitary of sleep-deprived rats by exogenous administration of hypothalamic thyrotropin-releasing hormone (TRH), however, results in a normal TSH response (C. A. Everson, unpublished observations), suggesting that the pituitary function is intact and that the hypothalamus might not be responding normally and releasing the TRH signal to the pituitary adequately. These animals have decreased hypothalamic metabolic activity that might be related to changes in TRH production and release.

The outcomes of sleep deprivation in animals and humans 
suggest disruption in some common and basic biological mechanisms like those occurring with deprivation of other essential biological requirements, such as food and water. The most marked consequence of sleep deprivation in humans appears to be impairment of cognitive performance; physical impairments, such as reduced physical endurance, have not been found even after 8-11 d of sleep loss (Horne, 1988). Few studies in humans have specifically addressed the effects of sleep deprivation on the energy requirements of the brain or body, but there are indications that metabolic factors play a critical role. For examplc, disruption of slccp in humans, whether imposed experimentally (Bonnet et al., 1991) or occurring spontaneously in insomnia (Bonnet et al., 1993), increases the whole-body metabolic rate during subsequent sleep. There have also been reports of alterations in nitrogen excretion (Scrimshaw et al., 1966), increased hunger (Fiorica et al., 1968; Rubin et al., 1968), and the sensation of feeling cold in sleep-deprived subjects, although disorders in thermoregulation have not been found (Horne, 1988).

Selective decreases in regional brain metabolism in humans after a short 34-hr period of sleep deprivation were observed by Buchsbaum and colleagues (1989); these changes were small and within the limited resolution possible with PET (positron emission tomography) appeared to be localized in the thalamus, basal ganglia, and cerebellum. As in the present study, no significant change was found in the average metabolic rate of the brain as a whole. This duration of sleep deprivation would not be expected to cause declines in cognitive performance that could not be overcome by increased motivation and willpower. Beyond 68-76 hr of sleep deprivation, however, enhanced incentives or an obvious desire to perform well do not help to overcome impaired cognitive performance, indicating that a more fundamental biological impairment has developed (Horne, 1988). No study of human cerebral metabolism during this later period of sleep deprivation has been reported to our knowledge.

\section{References}

Bergmann BM, Winter JB, Rosenberg RS, Rechtschaffen A (1987) NREM sleep with low-voltage EEG in the rat. Sleep 10:1-11.

Bergmann BM, Kushida CA, Everson CA, Gilliland MA, Obermeyer W, Rechschaffen A (1989a) Sleep deprivation in the rat. II. Methodology. Sleep 12:5-12.

Bergmann BM, Everson CA, Kushida CA, Fang VS, Leitch CA, Schoeller DA, Refetoff S, Rechtschaffen A (1989b) Sleep deprivation in the rat. V. Energy use and mediation. Sleep 12:31-41.

Bergmann BM, Seiden LS, Landis CA, Gilliland MA, Rechtschaffen A (1991) No effect of chronic sleep deprivation on rat brain monoamine levels. Sleep Res 20:404.

Blatteis CM (1990) Neuromodulative actions of cytokines. Yale J Biol Med 63:133-146.

Bonnet MH, Berry RB, Arand DL (1991) Metabolism during normal, fragmented, and recovery sleep. J Appl Physiol 71:1112-1118.

Bonnet MH, Arand DL, McNulty TB (1993) 24-hour metabolic rate in matched normals and insomniacs. Sleep Res 22:175.

Buchsbaum MS, Gillin JC, Wu J, Hazlett E, Sicotte N, Dupont RM, Bunney WE Jr (1989) Regional cerebral glucose metabolic rate in human sleep assessed by positron emission tomography. Life Sci 45 : 1349-1356.

Everson CA (1993) Sustained sleep deprivation impairs host defense. Am J Physiol 265:R 1148-R 1154.

Everson CA, Wehr TA (1993) Nutritional and metabolic adaptations to prolonged sleep deprivation in the rat. Am J Physiol 264:R376R387.

Everson CA, Bergmann BM, Rechtschaffen A (1988) Hypoalbuminemia and anemia in totally sleep deprived rats. Sleep Res 17:314.

Everson CA, Bergmann BM, Rechtschaffen A (1989a) Sleep deprivation in the rat. III. Total sleep deprivation. Sleep 12:13-21.
Everson CA, Gilliland MA, Kushida CA, Pilcher JJ, Fang VS, Refetoff S, Bergmann BM, Rechtschaffen A (1989b) Sleep deprivation in the rat. IX. Recovery. Sleep 12:60-67.

Everson CA, Smith CB, Sokoloff L, Jerrels SA, Wehr TA (1991) Local cerebral glucose utilization in freely moving rats during prolonged sleep loss. Sleep Res 20A:85.

Fiorica V, Higgins EA, Iampietro PF, Lategola MT, Davis AW (1968) Physiological responses of men during sleep deprivation. J Appl Physiol 24:167-176.

Gilliland M, Wold L, Wollmann R, Eschenbach K, Rechtschaffen A (1984) Pathology in sleep deprived rats is not reflected in histologic abnormalities. Sleep Res 13:190.

Goochee C, Rasband W, Sokoloff L (1980) Computerized densitometry and color coding of $\left[{ }^{14} \mathrm{C}\right]$ deoxyglucose autoradiographs. Ann Neurol 7:359-370.

Grossman SP (1976) Neuroanatomy of food and water intake. In: Hunger: basic mechanisms and clinical implications (Novin D, Wyrwicka W, Bray G, eds), pp 51-59. New York: Raven.

Hawkins RA, Williamson DH, Krebs HA (1971) Ketone-body utilization by adult and suckling rat brain in vivo. Biochem J 122:13-18.

Hori T, Nakashima T, Take S, Kaizuka Y, Mori T, Katafuchi T (1991) Immune cytokines and regulation of body temperature, food intake and cellular immunity. Brain Res Bull 27:309-313.

Horne J (1988) Why we sleep: the functions of sleep in humans and other mammals. New York: Oxford UP.

Kennedy C, Gillin JC, Mendelson W, Suda S, Miyaoka M, Ito M, Nakamura RK, Storch FI, Pettigrew K, Mishkin M, Sokoloff L (1982) Local cerebral glucose utilization in non-rapid eye movement sleep. Nature 297:325-327.

Kirk RE (1968) Experimental design: procedures for the behavioral sciences. Belmont, CA: Brooks/Cole.

Krebs HA, Williamson DH, Bates MW, Page MA, Hawkins RA (1971) The role of ketone bodies in caloric homeostasis. Adv Enzyme Regul 9:387-409.

Kripke DF, Simons RN, Garfinkel L, Hammond EC (1979) Short and long sleep and sleeping pills. Is increased mortality associated? Arch Gen Psychiatry 36:103-116.

Kushida CA, Everson CA, Suthipinittharm P, Sloan J, Soltani K, Bartnicke B, Bergmann BM, Rechtschaffen A (1989) Sleep deprivation in the rat. VI. Skin changes. Sleep 12:42-46.

Landis CA, Collins BJ, Cribbs LL, Sukhatme VP, Bergmann BM, Rechtschaffen A, Smalheiser NR (1993) Expression of Egr-1 in the brain of sleep deprived rats. Brain Res Mol Brain Res 17:300-306.

Miller NE, Bartus RT (1992) Sleep, sleep pathology, and psychopathology in later life: a new research frontier. Neurobiol Aging 3:283286.

Miller RG (1966) Simultaneous statistical inference. New York: McGraw Hill.

Moruzzi G (1966) The functional significance of sleep with particular regard to the brain mechanisms underlying consciousness. In: Brain and conscious experience (Eccles JC, ed), pp 345-388. New York: Springer.

Obermeyer W, Bergmann BM, Rechtschaffen A (1991) Sleep deprivation in the rat. XIV. Comparison of waking hypothalamic and peritoneal temperatures. Sleep 14:285-293.

Paxinos G, Watson C (1986) The rat brain in stereotaxic coordinates, 2d ed. New York: Academic.

Pilcher JJ, Bcrgmann BM, Fang VS, RefetoffS, Rechtschaffen A (1990) Sleep deprivation in the rat. XI. The effect of guanethidine-induced sympathetic blockade on the sleep deprivation syndrome. Sleep 13: 218-231.

Prete FR, Bergmann BM, Holtzman P, Obermeyer W, Rechtschaffen A (1991) Sleep deprivation in the rat. XII. Effect on ambient temperature choice. Sleep 14:109-115.

Rechtschaffen A, Gilliland MA, Bergmann BM, Winter JB (1983) Physiological correlates of prolonged sleep deprivation in rats. Science 221:182-184.

Robinson AM, Williamson DH (1980) Physiological roles of ketone bodies as substrates and signals in mammalian tissues. Physiol Rev 60:143-187.

Rubiny RT, Kollar EJ, Slater GG, Clark BR (1968) Excretion of 17hydroxycorticosteroids and vanillylmandelic acid during 205 hours of sleep deprivation in man. Psychosom Med 31:68-79.

Scheinberg P (1950) Cerebral circulation and metabolism in hyperthyroidism. J Clin Invest 29:1010-1013. 
Sclafani A (1976) Appetite and hunger in experimental obesity syndromes. In: Hunger: basic mechanisms and clinical implications (Novin D, Wyrwicka W, Bray G, eds), pp 281-295. New York: Raven.

Scrimshaw NS, Habicht JP, Pellet P, Piché ML, Cholakos B (1966) Effects of sleep deprivation and reversal of diurnal activity on protein metabolism of young men. Am J Clin Nutr 19:313-319.

Sensenbach W, Madison L, Eisenberg S, Ochs L (1954) The cerebral circulation and metabolism in hyperthyroidism and myxedema. $J$ Clin Invest 33:1434-1440.

Shibata M (1990) Hypothalamic neuronal responses to cytokines. Yale J Biol Med 63:147-156.

Smith CB, Goochee C, Rapoport SI, Sokoloff L (1980) Effects of ageing on local rates of cerebral glucose utilization in the rat. Brain 103:351365.

Sokoloff L (1977) Relation between physiological function and energy metabolism in the central nervous system. J Neurochem 29:13-26.

Sokoloff L (1985) Mapping local functional activity by measurement of local cerebral glucose utilization in the central nervous system of animals and man. Harvey Lect 79:77-143.

Sokoloff L (1989) Circulation and energy metabolism of the brain. In: Basic neurochemistry: molecular, cellular, and medical aspects, 4th ed (Siegel GJ, Agranoff BW, Albers RW, Molinoff PB, eds), pp 565590. New York: Raven.

Sokoloff L, Wechsler RL, Mangold R, Balls K, Kety SS (1953) Cerebral blood flow and oxygen consumption in hyperthyroidism before and after treatment. J Clin Invest 32:202-208.

Sokoloff L, Reivich M, Kennedy C, Des Rosiers MH, Patlak CS, Pettigrew KD, Sakurada O, Shinohara M (1977) The $\left[{ }^{14} \mathrm{C}\right]$ deoxyglucose method for the measurement of local cerebral glucose utilization: theory, procedure, and normal values in the conscious and anesthetized albino rat. J Neurochem 28:897-916.

Steriade M (1992) Basic mechanisms of sleep generation. Neurology 42[Suppl 6]:9-18.

Suda S, Shinohara M, Miyaoka M, I,ucignani G, Kennedy C, Sokoloff L (1990) The lumped constant of the deoxyglucose method in hypoglycemia: effects of moderate hypoglycemia on local cerebral glucose utilization in the rat. J Cereb Blood Flow Metab 10:499-509.

Szymusiak R, DeMory A, Kittrell EMW, Satinoff E (1985) Diurnal changes in thermoregulatory behavior in rats with medial preoptic lesions. Am J Physiol 249:R219-R227.

Szymusiak R, Danowski J, McGinty D (1991) Exposure to heat restores sleep in cats with preoptic/anterior hypothalamic cell loss. Brain Res 541:134-138.

Tsai L-L, Bergmann BM, Perry BD, Rechtschaffen A (1993) Effects of chronic total sleep deprivation on central noradrenergic receptors in rat brain. Brain Res 602:221-227.

Utiger RD (1987) Thyrotropin-releasing hormone and thyrotropin secretion. J Lab Clin Med 109:327-335. 